\title{
Tuberculose Pulmonar: O Desafio do Diagnóstico na Gravidez
}

\section{Pulmonary Tuberculosis: A Diagnostic and Management Challenge in Pregnancy}

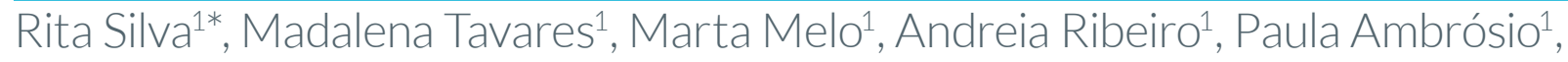
Paula Tapadinhas ${ }^{1}$

\section{RESUMO}

A tuberculose é uma doença infecciosa cuja prevalência tem vindo a diminuir significativamente em Portugal. Dos doentes infetados, apenas 10\% desenvolverão a doença, sendo este risco superior em populações imunocomprometidas. Os autores descrevem um caso de uma grávida, previamente saudável e sem contexto epidemiológico, cujo diagnóstico de tuberculose foi estabelecido às 32 semanas de gestação, após ter iniciado um quadro clínico inespecífico. A confirmação diagnóstica e a instituição da terapêutica anti-bacilar foram céleres permitindo um desfecho materno-fetal favorável. O parto decorreu às 36 semanas sem intercorrências. O recém-nascido iniciou de imediato quimioprofilaxia que manteve até confirmação de ausência de doença. A mãe manteve seguimento em consulta de Pneumologia no Centro de Doenças Pneumológico, com boa evolução clínica, radiológica e laboratorial, tendo tido alta sem doença ativa. A abordagem de uma grávida com suspeita de tuberculose deverá seguir a marcha diagnóstica habitual, nomeadamente com os exames imagiológicos necessários e com a instituição da terapêutica o mais precocemente possível.

PALAVRAS-CHAVE: Complicações Infecciosas na Gravidez; Gravidez; Tuberculose Pulmonar 


\section{ABSTRACT}

Tuberculosis is an infectious disease whose prevalence has been decreasing significantly in Portugal. Of the infected patients, only $10 \%$ will develop the disease, and this risk is higher in immunocompromised populations. The authors describe a case of a pregnant woman, previously healthy and without epidemiological context, whose diagnosis of tuberculosis was established at 32 weeks of gestation, after having started an unspecific symptom. The diagnostic confirmation and the establishment of anti-bacillary therapy were swift allowing a favorable maternal-fetal outcome. Delivery occurred at 36 weeks without complications. The newborn immediately started chemoprophylaxis, which was maintained until confirmation of absence of disease. The mother continued follow-up in a pulmonology consultation in the Center of Pneumological Diseases, with good clinical, radiological and laboratory evolution, having been discharged without active disease.

KEYWORDS: Pregnancy; Pregnancy Complications, Infectious; Tuberculosis, Pulmonary

\section{INTRODUÇÃO}

A tuberculose é uma doença infeciosa causada pelo Mycobacterium tuberculosis. ${ }^{1}$ Pode atingir qualquer órgão, sendo a forma pulmonar a mais frequente. ${ }^{1}$ Nos últimos 10 anos em Portugal assistiu-se a uma diminuição de cerca de $40 \%$ da taxa de notificação e de incidência da tuberculose, com valores de incidência na população geral abaixo dos 20/100 000 habitantes. ${ }^{2}$ Estima-se que a incidência na gravidez seja semelhante à da população geral, uma vez que a gravidez não está associada a aumento do risco da doença. Pela sua clínica inespecífica, o diagnóstico torna-se difícil impondo uma elevada suspeição clínica. ${ }^{3.4} \mathrm{~A}$ terapêutica deve ser iniciada o mais precocemente possível, minimizando, assim, os riscos materno-fetais. A terapêutica anti-bacilar de primeira linha é considerada segura na gravidez, sendo o risco de toxicidade ultrapassado pela vantagem do tratamento. ${ }^{5-8}$

\section{CASO CLÍNICO}

Mulher de 24 anos, melanodérmica, desempregada, multípara, sem antecedentes pessoais e familiares relevantes. Negava história de consumos aditivos, contactos anteriores com a doença e viagens recentes. Gravidez vigiada nos cuidados de saúde primários, sem intercorrências. Às 32 semanas e 5 dias recorreu ao serviço de urgência com queixas de algias pélvicas e tonturas. Negava febre, cansaço ou dispneia. Referia acessos esporádicos de tosse não produtiva. A utente encontrava-se normotensa, normocárdica e subfebril. O exame ginecológico, toque vaginal, ecografia obstétrica e tocograma não revelaram alterações. À auscultação pulmonar constatou-se a diminuição do murmúrio vesicular à direita e analiticamente a elevação dos parâmetros in- flamatórios (leucocitose com linfocitose e monocitose e elevação da PCR - proteína C reativa). A radiografia tórax revelou uma condensação na base direita com infiltrado micronodular difuso sugestivo de cavitações nos terços médios e superiores (Fig. 1). Para esclarecimento diagnóstico foi realizada uma tomografia computorizada (TC) torácica que constatou a presença de múltiplas opacidades pulmonares bilaterais de provável natureza inflamatória, com extensas cavitações internas, a maior no lobo superior direito, associado a um espessamento intersticial peribroncovascular difuso bilateral e áreas extensas de confluência no lobo médio e lobos superiores, sugestivas de alterações inflamatórias em atividade (Fig. 2). A presença de bacilos álcool-ácido resistentes na expetoração em três amostras consecutivas e o isolamento do bacilo de Koch (BK) no exame cultural confirmaram o diagnóstico: tuberculose pulmonar (TP). Perante a suspeita, foi instituída de imediato terapêutica anti-bacilar com isonizida, rifampicina e etambulol cum-

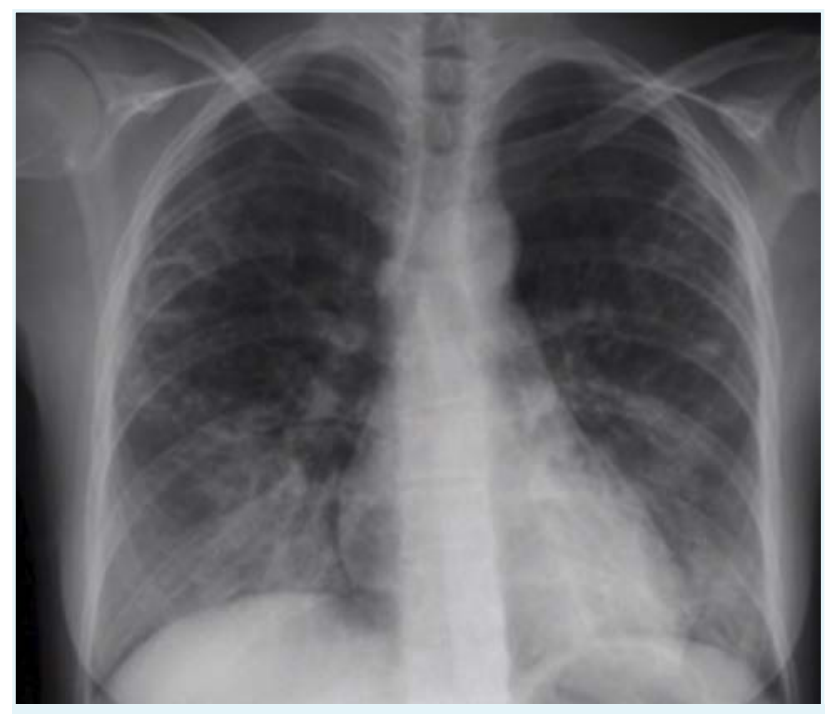

FIGURA 1. Radiografia tórax. 

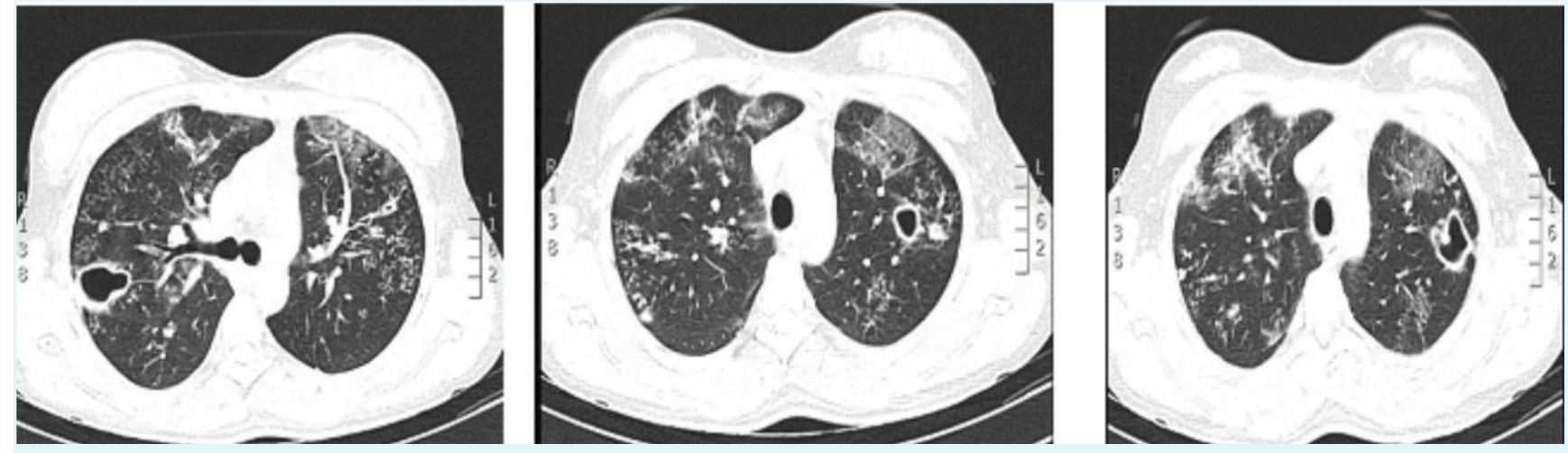

FIGURA 2. Cortes da tomografia computorizada torácica.

prindo isolamento de contacto. Iniciou suplemento de 10 mg/dia de vitamina B6 (piridoxina). Manteve-se clinicamente estável e verificou-se uma evolução favorável. Foi assegurada a vigilância do bem-estar fetal com auscultação diária do foco fetal. Ao $26^{\circ}$ dia de terapêutica, após a baciloscopia ter sido negativa em três amostras e ultrapassado o período de contágio, a grávida teve alta referenciada à consulta de Alto Risco e ao Centro de Diagnóstico Pneumaológico (CDP). Na alta foi realizada ecografia para avaliação do feto que constatou a presença de feto único, cefálico, crescimento no percentil 51 com dinâmica fetal, líquido amniótico e circulação fetal normais. O parto decorreu espontaneamente às 36 semanas e 3 dias, sem intercorrências à exceção da prematuridade tardia, com o nascimento de um recém-nascido com boa vitalidade e peso adequado à idade gestacional (2640 g, índice Apgar 10/10/10). Foi excluída tuberculose congénita com a realização de radiografia tórax que foi normal, a prova de Mantoux, hemoculturas para BK e PCR para BK no suco gástrico e urina negativas. De acordo com o preconizado cumpriu quimioprofilaxia com isoniazida e manteve seguimento em consulta de Pediatria. A mãe e o recém-nascido tiveram alta ao terceiro dia. A doente manteve seguimento no CDP e cumpriu a terapêutica anti-bacilar, tendo tido alta com resolução da doença.

\section{DISCUSSÃO}

A gravidez não é uma condição predisponente para o desenvolvimento ou progressão da tuberculose pulmonar. ${ }^{9}$ Contudo, merece especial atenção pelo risco de tuberculose congénita e neonatal bem como a morbilidade obstétrica associada, nomeadamente aborto espontâneo, restrição crescimento fetal, pré-eclâmpsia, hemorragia pós-parto, parto pré-termo e fetos com baixo peso ao nascimento., $3,5,10 \mathrm{O}$ diagnóstico é, muitas vezes tardio pela apresentação insidiosa da doença e sin- tomas inespecíficos, mimetizando os próprios sintomas da gravidez. O caso clínico demostra que apesar da inespecificidade dos sintomas, a importância de um exame objetivo completo e a valorização dos fatores demográficos, mesmo numa doente sem contexto epidemiológico, é fulcral para a instituição de um diagnóstico célere. ${ }^{6}$ Perante a suspeita de tuberculose pulmonar, a marcha diagnóstica deve seguir o algoritmo habitual, incluindo a realização de exames de imagem., ${ }^{3,11}$ Assim sendo, o tratamento não pode ser diferido pela presença de uma gravidez e deve ser independente da idade gestacional. Relativamente à realização de exames de radiação diagnóstica é conhecido que a dose de radiação absorvida é bastante reduzida, não constituindo risco para o feto. A maioria dos exames de radiologia diagnóstica expõe o útero a doses de radiação inferiores a 20 mGy, sendo que a dose absorvida da radiografia tórax é 0,0005-0,01 mGy e da TC torácica de 0,01-0,66 mGy (Tabela 1).12,13 É considerado como limiar para a ocorrência de algum efeito do tipo determinístico a dose de radiação de 50 mGy, pelo que a dose associada aos exames realizados no caso, consideram-se nulos. Ainda assim, é importante o uso de protetores de chumbo sobre o abdómen e utilização de técnicas de baixa dosagem. ${ }^{12} \mathrm{O}$ atraso no diagnóstico pela não utilização de exames radiológicos é, por si só, mais nocivo para a saúde materna e fetal do que os potenciais riscos da utilização de radiação. ${ }^{6,12} \mathrm{~A}$ terapêutica preconizada é múltipla e prolongada devendo ser instituída o mais precocemente possível, sendo os fármacos de primeira linha - isoniazida, rifampicina e etambulol - seguros na gravidez. ${ }^{1,8,9}$ É recomendada a suplementação com vitamina B6 em associação à isoniazida para prevenção de neuropatia periférica. ${ }^{3,9} \mathrm{~A}$ estreptomicina e pirazimanida não são recomendadas, uma vez que, os seus efeitos no feto ainda não foram estudados. ${ }^{8}$ A amamentação é reconhecida como segura devendo ser encorajada nas mulheres sob terapêutica de primeira linha., ${ }^{3,710}$ Este caso ilustra a importância da existência de uma equipa multidisciplinar e do estabele- 
TABELA 1. Doses de exposição fetal a radiação nos exames radiológicos mais frequentes.

\begin{tabular}{|c|c|}
\hline Exame imagiológico & $\begin{array}{l}\text { Dose absorvida } \\
\text { (mGy) }\end{array}$ \\
\hline $\begin{array}{l}\text { Exames de muito baixa dose (<0,1 mGy) } \\
\text { Radiografia coluna cervical } \\
\text { Radiografia membros } \\
\text { Mamografia (duas incidências) } \\
\text { Radiografia tórax (duas incidências) }\end{array}$ & $\begin{array}{l}<0,001 \\
<0,001 \\
0,001-0,01 \\
0,0005-0,01\end{array}$ \\
\hline $\begin{array}{l}\text { Exames de dose baixa a média (0,1-10 mGy) } \\
\text { Radiografia } \\
\text { Radiografia abdominal } \\
\text { Radiografia coluna lombar }\end{array}$ & $\begin{array}{l}0,1-3.0 \\
1,0-10\end{array}$ \\
\hline $\begin{array}{l}\text { Tomografia computorizada (TC) } \\
\text { Cabeça e pescoço } \\
\text { Tórax }\end{array}$ & $\begin{array}{l}1-10 \\
0,01-0,66\end{array}$ \\
\hline $\begin{array}{l}\text { Medicina Nuclear } \\
\text { Cintigrafia óssea (Tc-99m) } \\
\text { Angiografia pulmonar }\end{array}$ & $\begin{array}{l}4-5 \\
0,5\end{array}$ \\
\hline $\begin{array}{l}\text { Exames de alta dose (10-50 mGy) } \\
\text { TC Abdominal } \\
\text { TC Pélvico } \\
\text { PET/TC }\end{array}$ & $\begin{array}{l}1,3-35 \\
10-50 \\
10-50\end{array}$ \\
\hline
\end{tabular}

Tabela modificada de Committee Opinion No. 723: Guidelines for Diagnostic Imaging During Pregnancy and Lactation. Obstet Gynecol. 2017;130:e210-6.

cimento de um diagnóstico célere com a instituição precoce da terapêutica numa patologia que, quando diagnosticada tardiamente ou subdiagnosticada, se associa a uma morbimortalidade materno-fetal significativa. ${ }^{6,10}$

\section{CONCLUSÃO}

Apesar da incidência ser baixa nos países desenvolvidos, a TP continua a ser um problema de saúde pública nas mulheres em idade reprodutiva., ${ }^{2,3} \mathrm{Na}$ gravidez a apresentação da doença é tipicamente insidiosa e, por isso, requer um elevado índice de suspeição. Perante a suspeita de tuberculose, importa realçar que a marcha diagnóstica deve seguir o algoritmo habitual com a instituição da terapêutica o mais precocemente possível. Os anti-bacilares de primeira linha são seguros na gravidez e amamentação. ${ }^{3,6,8,12}$ Apesar da gravidez não alterar o curso natural da doença, não constituindo por isso as grávidas uma população de risco, sabemos que o subdiagnóstico e o consequente atraso no tratamento aumentam significativamente a morbilidade materna e neonatal com consequentes desfechos desfavoráveis.

\section{APRESENTAÇÕES E PRÉMIOS}

Comunicação oral apresentada no $4^{\circ}$ Congresso do Internado Médico da José de Mello Saúde - Vencedora do Prémio do $1^{\circ}$ Lugar na rúbrica "Show your cases - Prova de Caras".

\section{RESPONSABILIDADES ÉTICAS}

CONFLITOS DE INTERESSE: Os autores declaram a inexistência de conflitos de interesse na realização do presente trabalho.

FONTES DE FINANCIAMENTO: Não existiram fontes externas de financiamento para a realização deste artigo.

CONFIDENCIALIDADE DOS DADOS: Os autores declaram ter seguido os protocolos da sua instituição acerca da publicação dos dados de doentes.

CONSENTIMENTO: Consentimento do doente para publicação obtido.

PROVENIÊNCIA E REVISÃO POR PARES: Não comissionado; revisão externa por pares.

\section{ETHICAL DISCLOSURES}

CONFLICTS OF INTEREST: The authors have no conflicts of interest to declare.

FINANCING SUPPORT: This work has not received any contribution, grant or scholarship.

CONFIDENTIALITY OF DATA: The authors declare that they have followed the protocols of their work center on the publication of data from patients.

PATIENT CONSENT: Consent for publication was obtained.

PROVENANCE AND PEER REVIEW: Not commissioned; externally peer reviewed.

\section{REFERÊNCIAS}

1. Rick Stapledon, Simon Cameron, Paul Goldwater. Tuberculosis in pregnancy. South Australian Perinatal Practice Guideline. Adelaide: Department for Health and Wellbeing, Government of South Australia; 2014.

2. Direcção-Geral da Saúde. Programa Nacional para a Infeção VIH, SIDA e Tuberculose. Portugal: infeção VIH, SIDA e tuberculose em números. Lisboa: DGS; 2014

3. Kwan BC, Yu Y, Goldberg H. A case of tuberculosis in a pregnant woman and review of current literature. Obstet Med. 2010; 3:161-3. doi: 10.1258/om.2010.100008.

4. Bishara H, Vinitsky O, Salim R, Keness Y, Chazan B, Miron D. Tuberculosis in pregnancy and the puerperium. Harefuah. 2013;152:381-4,435.

5. Guideline - Treatment of tuberculosis in pregnant women and newborn infants. Queensland Health. Version 3.1. 2016. [consultado Jan 2020] Disponível em: https://www.health.qld.gov. au/_data/assets/pdf_file/0030/444558/tb-guideline-pregnancy.pdf.

6. Medchill MT, Gillum M. Diagnosis and management of tuberculosis during pregnancy. Obstet Gynecol Surv. 1989;44:81-4. doi: 10.1097/00006254-198902000-00001.

7. Padmapriyadarsini C, Shri Vijay Bala Yogendra S, Joseph B, Murali L. Multidrug resistant tuberculosis during pregnancy. Indian J Tuberc. 2017;64:63-4. doi: 10.1016/j.ijtb.2016.09.018. 
8. Centers for Disease Control and Prevention. Tuberculosis and pregnancy. [consultado Jan 2020] Disponível em: http://www. cdc.gov/tb/topic/populations/pregnancy/default.htm.

9. Mendes-Graça L. Patologia respiratória da gravidez. In: Medicina Materno-fetal. $5^{a}$ ed. Lisboa: Lidel; 2017. p. 507-8.

10. Loto OM, Awowole I. Tuberculosis in pregnancy: a review. J Pregnancy. 2012;2012:379271. doi: 10.1155/2012/379271.

11. Alcobia C, Costa S. Tuberculose na grávida: um relato de caso. Rev Port Med Geral Familiar. 2006; 32. doi.org/10.32385.

12. Batista E, Domingues A, Duarte H, Vasco E, Moura P. Safety of imagiologic exams in pregnancy. Acta Obstet Ginecol Port. 2014:8:176-85.

13. Committee Opinion No. 723: Guidelines for Diagnostic Imaging During Pregnancy and Lactation. Obstet Gynecol. 2017;130:e210-e216. doi: 10.1097/ AOG.0000000000002355. 